\title{
Prognosis in HIV-infected patients with non-small cell lung cancer
}

\author{
$\mathrm{K}$ Sigel $^{\star, 1}, \mathrm{~K}$ Crothers $^{2}$, R Dubrow ${ }^{3}, \mathrm{~K} \mathrm{Krauskopf}^{1}, \mathrm{~J} \mathrm{Jao}^{1}, \mathrm{C} \mathrm{Sigel}^{4}, \mathrm{~A} \mathrm{Moskowitz}^{5}$ and J Wisnivesky ${ }^{1}$ \\ ${ }^{1}$ Division of General Internal Medicine, Mount Sinai School of Medicine, New York, NY, USA; ${ }^{2}$ Department of Internal Medicine, \\ Division of Pulmonary and Critical Care Medicine, University of Washington School of Medicine, Seattle, WA, USA; ${ }^{3}$ Yale School of \\ Public Health and Yale School of Medicine, New Haven, CT, USA; ${ }^{4}$ Department of Pathology, Memorial Sloan-Kettering \\ Hospital, New York, NY, USA and ${ }^{5}$ Department of Health Evidence and Policy, Mount Sinai School of Medicine, New York, \\ NY, USA
}

Background: We conducted a population-based study to evaluate whether non-small cell lung cancer (NSCLC) prognosis was worse in HIV-infected compared with HIV-uninfected patients.

Methods: Using the Surveillance, Epidemiology and End Results (SEER) registry linked to Medicare claims, we identified 267 HIV-infected patients and 1428 similar controls with no evidence of HIV diagnosed with NSCLC between 1996 and 2007. We used conditional probability function (CPF) analyses to compare survival by HIV status accounting for an increased risk of non-lung cancer death (competing risks) in HIV-infected patients. We used multivariable CPF regression to evaluate lung cancer prognosis by HIV status adjusted for confounders.

Results: Stage at presentation and use of stage-appropriate lung cancer treatment did not differ by HIV status. Median survival was 6 months (95\% confidence interval (CI): 5-8 months) among HIV-infected NSCLC patients compared with 20 months (95\% Cl: 17-23 months) in patients without evidence of HIV. Multivariable CPF regression showed that HIV was associated with a greater risk of lung cancer-specific death after controlling for confounders and competing risks.

Conclusion: NSCLC patients with HIV have a poorer prognosis than patients without evidence of HIV. NSCLC may exhibit more aggressive behaviour in the setting of HIV.

Persons with human immunodeficiency virus (HIV) infection have a greater risk of lung cancer compared with the general population (Shiels et al, 2009; Sigel et al, 2012). Although higher smoking rates in HIV-infected persons account for some of this increased risk (Kirk \& Merlo, 2011), studies have also implicated HIV-related immunosuppression as an independent risk factor for the development of lung cancer (Guiguet et al, 2009). It is not clear, though, if HIV infection influences the prognosis of lung cancer.

Studies from the pre-antiretroviral era reported poor survival rates in HIV-infected lung cancer patients (Tirelli et al, 2000; Biggar et al, 2005). These findings were strongly influenced by high rates of acquired immunodeficiency syndrome (AIDS)-related deaths, a mortality pattern that existed prior to the introduction of combination antiretroviral therapy (cART). More recent data suggest improving outcomes among HIV-infected patients with lung cancer, although survival appears to still be worse than in patients without HIV infection (Hakimian et al, 2007; Suneja et al, 2013).

Worse lung cancer survival in HIV-infected patients may be explained by more aggressive cancer behaviour. Accelerated progression of cancers in HIV-infected patients has been observed in studies of a diverse range of non-AIDS-defining malignancies including hepatocellular carcinoma, melanoma, and Hodgkin's lymphoma (Poluri et al, 2002; Rodrigues et al, 2002; Bourcier et al, 2012). Furthermore, poor long-term colorectal cancer outcomes have been observed in organ transplant patients on chronic immunosuppressive therapy (Buell et al, 2005). Thus, an impaired T-cell response, whether caused by HIV infection or immunosuppressive drugs, may blunt immune-related cancer defenses, leading to more rapid cancer dissemination (O'Callaghan et al, 2010). 
Competing risks of mortality from other causes may also result in shorter overall survival (OS) in HIV-infected lung cancer patients. Although deaths related to AIDS-defining conditions have decreased markedly among HIV-infected persons on effective cART (Mocroft et al, 2002), mortality rates remain higher than in the general population (Zwahlen et al, 2009). Thus, it remains difficult to determine the independent effect of HIV infection on lung cancer prognosis, as HIV-infected lung cancer patients die from multiple other competing causes of death at a higher rate than do lung cancer patients who are not HIV-infected (Shiels et al, 2010).

In this study, we used data from a cART-era, nationally representative sample of patients with non-small cell lung cancer (NSCLC) to determine if HIV infection is associated with poorer lung cancer prognosis, accounting for lung cancer stage at presentation, use of stage-appropriate therapy, and competing risks of mortality.

\section{METHODS}

Study population. Our study used data from the Surveillance, Epidemiology, and End Results (SEER) cancer registries linked to Medicare claims. From this database, we identified 145515 cARTera cases of primary, incident NSCLC diagnosed prior to autopsy between years 1996 and 2007. Among these cases, we excluded those enrolled in healthcare maintenance organisations or those lacking part B Medicare insurance (coverage for outpatient care), as we could not ascertain comorbidities and use of chemotherapy for these patients (Klabunde et al, 2006). From this sample of 118370 cases, we identified patients with a diagnosis of HIV or AIDS based on Medicare inpatient, physician, and outpatient ICD-9 codes (42.XX, V57) using a validated algorithm (Fasciano et al, 1998; Klabunde et al, 2006). This algorithm required a minimum of two outpatient claims or one inpatient claim with relevant ICD-9 codes to establish an HIV/AIDS diagnosis as $>30 \%$ of persons with HIV-related claims had only one outpatient coding episode, suggestive of 'rule out' diagnoses (Klabunde et al, 2006). Many HIV-infected patients in the initial sample became eligible for Medicare benefits because of disability (Unites States Social Security Administration, 2013), as opposed to the majority of subjects within the SEER-Medicare database who obtained their benefits at age 65 years. Therefore, to create an appropriate comparison group, we matched each HIV-infected lung cancer patient with up to six lung cancer controls (without any HIV-related claims) by reason for Medicare entitlement (disability or achieved age 65 years), age (within 3 years), sex, and year of cancer diagnosis. Our final analytic sample included 1695 patients, consisting of $267 \mathrm{HIV}$-infected lung cancer patients and 1428 lung cancer controls with no evidence of HIV infection.

Study variables. Sociodemographic variables (age, sex, race/ ethnicity, marital status, and median income in zip code area of residence) and tumour characteristics (stage and histology) were obtained from SEER. Using Medicare data, we calculated modified Charlson comorbidity scores to quantify patients' burden of comorbid illnesses (Deyo et al, 1992). The comorbidities used to calculate this score were identified among patients' Medicare claims during the year prior to lung cancer diagnosis, but excluding the 30 days immediately prior to diagnosis. Surgical resection was ascertained using relevant SEER codes as well as Medicare claims. Administration of radiotherapy (RT) was also established using both data sources (Virnig et al, 2002). Treatment with chemotherapy was identified using a validated algorithm capturing Medicare claims for appropriate chemotherapeutic drugs (Warren et al, 2002). Claims administered 90 days before patients' lung cancer diagnosis through 30 days following cancer diagnosis relating to home medical services and nursing home use were also identified as proxies for performance status (Wisnivesky et al, 2011).

Survival data were obtained from both SEER and Medicare, which have high levels of accurate death ascertainment (Bach et al, 2002). Cause of death (lung cancer vs non-lung cancer) was collected from SEER, and was based on death certificate data (NCI.gov, 2013). Lung cancer death-specific, competing risk survival analyses used SEER survival data and patients were censored if no death was noted in SEER by 31st December 2007. The OS analyses utilised Medicare death data, as it contained additional follow-up time, and were censored on 31st December 2009.

Statistical analysis. We compared baseline characteristics and causes of death for patients with and without evidence of HIV infection using the $\chi^{2}$-test. Median OS and 5-year survival rates by HIV status were estimated using the Kaplan-Meier method. To control for major prognostic factors, we repeated these analyses stratifying by stage (I-IIIA and IIIB-IV) and treatment (stageappropriate treatment and no treatment). Stage-appropriate treatment was defined by National Comprehensive Cancer Network criteria (NCCN, 2011) and included surgery for stages I-IIIA (followed by adjuvant chemotherapy for stage II-IIIA disease), combined chemotherapy and RT for stage IIIB disease, and chemotherapy for stage IV NSCLC. To assess differences in OS accounting for potential confounders, we fit Cox models using HIV as our primary exposure of interest, adjusting for year of cancer diagnosis, age, sex, race/ethnicity, marital status, median income in zip code area of residence, reason for Medicare entitlement, comorbidity score, cancer stage, tumour histologic subtype, use of stage-appropriate treatment, nursing home residence, and use of home medical services. We conducted sensitivity analyses limited to patients diagnosed after 2001 to evaluate outcomes of HIV patients treated after the availability of more potent antiretroviral combinations.

Given expected differences in life expectancy for NSCLC patients by HIV status, we used conditional probability function (CPF) methods to estimate the effect of HIV infection on lung cancer prognosis while appropriately accounting for competing risks (Pintilie, 2006; Allignol et al, 2011). The CPF methods determine the risk of lung cancer mortality given that patients do not die from competing causes of death. When the risk of competing events is large (as would be expected among HIV-infected patients), CPF techniques are preferred over KaplanMeier methods (which over-estimate cumulative incidence of the event of interest) or other competing risks methods (Pintilie, 2006; Allignol et al, 2011). We plotted CPF curves to assess the risk of death from lung cancer and tested for differences in survival by HIV status using the methods proposed by Pepe and Mori (Pepe \& Mori, 1993). As with our survival analyses, we then stratified this analysis by stage groups and use of stage-appropriate treatment. To assess the association of HIV infection and lung cancer prognosis adjusted for potential confounders, we fitted a multivariable conditional probability regression model. This model estimated proportional odds for factors potentially affecting the conditional probability of lung cancer death after controlling for competing risks (Allignol et al, 2011).

All analyses were performed in STATA Version 10 (Stata Corporation, College Station, TX, USA) and R Version 2.15.1 (R Development Core Team, Vienna, Austria). This study was approved by the Mount Sinai School of Medicine Institutional Review Board.

\section{RESULTS}

The study sample comprised $267 \mathrm{HIV}$-infected NSCLC patients and a comparison group of 1428 NSCLC patients without evidence 
of HIV infection. As expected, both groups had similar distribution of the characteristics used for matching (year of diagnosis, age, sex, and reason for Medicare entitlement) (Table 1). The HIV-infected

\begin{tabular}{|c|c|c|c|}
\hline Characteristic & $\begin{array}{c}\text { HIV } \\
\text { infected } \\
\mathbf{N}(\%)\end{array}$ & $\begin{array}{l}\text { No evidence of } \\
\text { HIV infection } \\
\boldsymbol{N}(\%)\end{array}$ & $P$-value \\
\hline \multicolumn{4}{|l|}{ Age, years } \\
\hline $\begin{array}{l}<50 \\
50-65 \\
65-75 \\
>75\end{array}$ & $\begin{array}{r}80(30) \\
115(43) \\
59(22) \\
13(5)\end{array}$ & $\begin{array}{l}345(24) \\
642(45) \\
370(26) \\
71(5)\end{array}$ & 0.2 \\
\hline Female & $34(13)$ & $169(14)$ & 0.6 \\
\hline \multicolumn{4}{|l|}{ Race/Ethnicity } \\
\hline $\begin{array}{l}\text { White } \\
\text { African-American } \\
\text { Hispanic } \\
\text { Other }\end{array}$ & $\begin{aligned} & 146(55) \\
& 99(37) \\
\geqslant & 11(\geqslant 5)^{a} \\
\leqslant & 11(\leqslant 5)^{a}\end{aligned}$ & $\begin{array}{l}787(55) \\
393(28) \\
113(8) \\
135(10)\end{array}$ & 0.001 \\
\hline \multicolumn{4}{|l|}{ Marital status } \\
\hline Married & $44(17)$ & $764(54)$ & $<0.001$ \\
\hline \multicolumn{4}{|c|}{ Median income in zip code } \\
\hline $\begin{array}{l}\text { Lowest quartile } \\
\text { Second quartile } \\
\text { Third quartile } \\
\text { Highest quartile }\end{array}$ & $\begin{array}{r}141(53) \\
44(17) \\
47(18) \\
35(13)\end{array}$ & $\begin{array}{l}552(39) \\
341(24) \\
298(21) \\
236(17)\end{array}$ & $<0.001$ \\
\hline \multicolumn{4}{|c|}{ Reason for Medicare entitlement } \\
\hline $\begin{array}{l}\text { Age }>65 \text { years } \\
\text { Disability or end-stage } \\
\text { renal disease }\end{array}$ & $\begin{array}{r}46(17) \\
221(83)\end{array}$ & $\begin{array}{r}275(19) \\
1153(81)\end{array}$ & 0.4 \\
\hline \multicolumn{4}{|c|}{ Year of lung cancer diagnosis } \\
\hline $\begin{array}{l}1996-1999 \\
2000-2003 \\
2004-2007\end{array}$ & $\begin{array}{r}42(16) \\
111(42) \\
114(43)\end{array}$ & $\begin{array}{l}210(15) \\
589(41) \\
629(44)\end{array}$ & 0.9 \\
\hline \multicolumn{4}{|c|}{ Modified Charlson comorbidity score } \\
\hline $\begin{array}{l}<1 \\
1-2 \\
2-4 \\
\geqslant 4\end{array}$ & $\begin{array}{r}171(64) \\
58(22) \\
26(10) \\
12(5)\end{array}$ & $\begin{array}{c}1,061(79) \\
215(15) \\
104(7) \\
48(3)\end{array}$ & $<0.01$ \\
\hline Histology & & & 0.4 \\
\hline $\begin{array}{l}\text { Adenocarcinoma } \\
\text { Squamous cell carcinoma } \\
\text { Large cell carcinoma } \\
\text { Other }\end{array}$ & $\begin{array}{l}131(49) \\
85(32) \\
20(8) \\
31(12)\end{array}$ & $\begin{array}{l}687(48) \\
512(36) \\
81(6) \\
148(10)\end{array}$ & \\
\hline \multicolumn{4}{|l|}{ Tumour stage } \\
\hline $\begin{array}{l}\text { I } \\
\text { II } \\
\text { IIIA } \\
\text { IIIB } \\
\text { IV }\end{array}$ & $\begin{array}{c}56(21) \\
12(5) \\
34(13) \\
57(21) \\
108(41)\end{array}$ & $\begin{array}{c}332(23) \\
95(7) \\
193(14) \\
267(19) \\
541(38)\end{array}$ & 0.5 \\
\hline Nursing home resident & $36(14)$ & $84(6)$ & $<0.001$ \\
\hline Home medical services & $\leqslant 11(\leqslant 5)^{a}$ & $37(3)$ & 0.5 \\
\hline
\end{tabular}

patients were more likely to be African-American $(P=0.001)$ and to reside in lower-income zip codes $(P<0.001)$, and less likely to be married $(P<0.001)$. Patients with HIV had higher comorbidity scores $(P<0.01)$ and were more likely to reside in a nursing home $(P<0.001)$ but not more likely to receive home medical services $(P=0.5)$ than patients without evidence of HIV infection. The distribution of tumour histologic subtype $(P=0.4)$ and cancer stage $(P=0.5)$ at presentation did not differ significantly by HIV status. Patterns of stage-appropriate treatment also did not differ by HIV status (Table 2); patients with stage I-IIIA NSCLC with HIV infection and with no evidence of HIV infection were treated with surgical resection with similar frequency $(P=0.1)$. Use of radiotherapy and chemotherapy in advanced disease (stage IIIB-IV) was also similar in both groups $(P=0.8)$.

Eight-two percent of HIV-infected NSCLC patients died from any cause during follow-up compared with $66 \%$ of NSCLC patients with no evidence of HIV infection $(P<0.001$; Table 3$)$. A greater proportion of HIV-infected patients died from non-lung cancer causes than did patients without evidence of HIV (31\%vs 9\%; $P<0.001)$.

Survival analysis. The OS was worse in patients with HIV and NSCLC compared with NSCLC patients without evidence of HIV infection (Figure 1A); $P<0.001$. Patients with HIV and NSCLC had a median OS of 6 months (95\% confidence interval (CI): 5-8 months), compared with 20 months (95\% CI: 17-23 months) in NSCLC patients with no evidence of HIV infection. The 5-year OS rate was 9\% (95\% CI: $6-13 \%)$ and $23 \%$ (95\% CI: $21-26 \%$ ) for patients with HIV infection and patients with no evidence of HIV infection, respectively. The OS was worse in HIV-infected patients compared with patients with no evidence of HIV infection within each stratification category $(P<0.001$ in each stratum): stage I-IIIA (Figure 1B), stage IIIB-IV (Figure 1C), stage-appropriate treatment (Figure 1D), and no treatment (Figure 1E). Cox regression analysis showed that HIV was associated with greater

Table 2. Frequency of treatment modalities by HIV status

\begin{tabular}{|l|c|c|c|}
\hline & $\begin{array}{c}\text { HIV } \\
\text { infected } \\
\mathbf{N}(\%)\end{array}$ & $\begin{array}{c}\text { No evidence of } \\
\text { HIV infection } \\
\mathbf{N}(\%)\end{array}$ & $\boldsymbol{P}$-value \\
\hline
\end{tabular}

Stage I-IIIA ( $\mathbf{N}=102$ HIV-infected; 620 with no evidence of HIV infection) ${ }^{\mathrm{a}}$

\begin{tabular}{|l|c|c|c|}
\hline Surgery $^{\mathbf{b}}$ & $57(56)$ & $396(64)$ & 0.1 \\
$\begin{array}{l}\text { Adjuvant chemotherapy } \\
\text { Radiation therapy for }\end{array}$ & $24(24)$ & $104(17)$ & 0.1 \\
$\begin{array}{l}\text { unresected tumours } \\
\text { Adjuvant } \\
\text { chemoradiotherapy } \\
\text { No treatment }\end{array}$ & $13(13)$ & $146(24)$ & 0.8 \\
\hline
\end{tabular}

Stage IIIB-IV ( $\mathbf{N}=165$ HIV infected; 808 with no evidence of HIV infection)

\begin{tabular}{|c|c|}
\hline $\begin{array}{l}\text { Radiation and } \\
\text { chemotherapy }\end{array}$ & $42(26)$ \\
\hline $\begin{array}{l}\text { Lone radiation or lone } \\
\text { chemotherapy }\end{array}$ & $73(44)$ \\
\hline No treatment & $50(30)$ \\
\hline \multicolumn{2}{|c|}{ 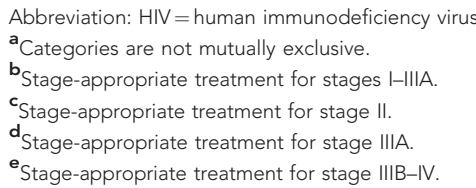 } \\
\hline
\end{tabular}


all-cause mortality (Table 4; hazard ratio: 1.9; 95\% CI: 1.6-2.2) after adjusting for potential confounders.

Conditional probability analysis. The CPF curves showing the risk of lung cancer death conditional on no death from competing causes are shown in Figure 2. The HIV-infected patients had worse lung cancer survival compared with patients without evidence of HIV $(P<0.001$; Figure 2A). As with OS, lung cancer-specific survival was worse in HIV-infected patients compared with patients with no evidence of HIV infection within each stratification category, with each stratum-specific $P$-value $<0.001$ (Figures 2B-E).

Competing risk proportional odds regression. In our adjusted survival analysis accounting for competing risks of death, HIVinfected NSCLC patients had a greater risk of lung cancer death than NSCLC patients with no evidence of HIV infection (Table 4; odds ratio: 1.7 ; $95 \% \mathrm{CI}$ : $1.1-2.3$ ) after controlling for potential confounders.

Sensitivity analyses. To assess the effect of more recent potent antiretroviral therapies on lung cancer outcomes, we conducted analyses limited to patients diagnosed with lung cancer in the most

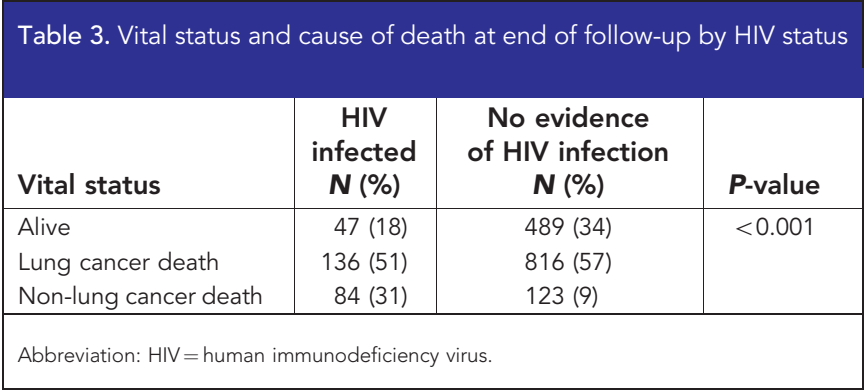

recent 6 years of study data (2002-2007). We compared OS and lung cancer-specific survival (as measured using CPF curves) by HIV status, stratified by the same categories as above, and observed trends similar to those observed for all diagnosis years $(P<0.001$ for all comparisons, not otherwise shown).

\section{DISCUSSION}

This study of population-based cART-era data showed that HIVinfected patients with NCSLC had poorer lung cancer-specific survival than patients with no evidence of HIV infection after accounting for potential confounding factors and competing risks of death. Our findings suggest that the natural history of lung cancer may be more aggressive in patients with HIV. Further assessment of the role of HIV-related immunosuppression in mediating lung cancer prognosis is warranted, as the approach to HIV management in HIV-infected patients with NSCLC may affect their oncologic course.

Large studies of lung cancer survival in HIV-infected patients in the cART-era have demonstrated mixed results. The results of our analysis are consistent with a large cART-era study of lung cancer prognosis in $337 \mathrm{HIV}$-infected lung cancer patients in the Texas Cancer Registry. This study found poorer OS and lung cancerspecific survival among HIV-infected NSCLC cases compared with cases without HIV (Suneja et al, 2013). Similar to our findings, OS and lung cancer-specific survival were worse in HIV-infected patients among NSCLC cases who did or did not receive lung cancer treatment. Our findings differ however, from a previous SEER-Medicare analysis that found no difference in OS in cARTera NSCLC patients with HIV infection $v s$ patients without evidence of HIV (Rengan et al, 2012). The different survival results between our study and the study by Rengan et al (2012) may be explained by the different algorithms used to identify HIV-infected patients in the two studies. We used a validated algorithm that
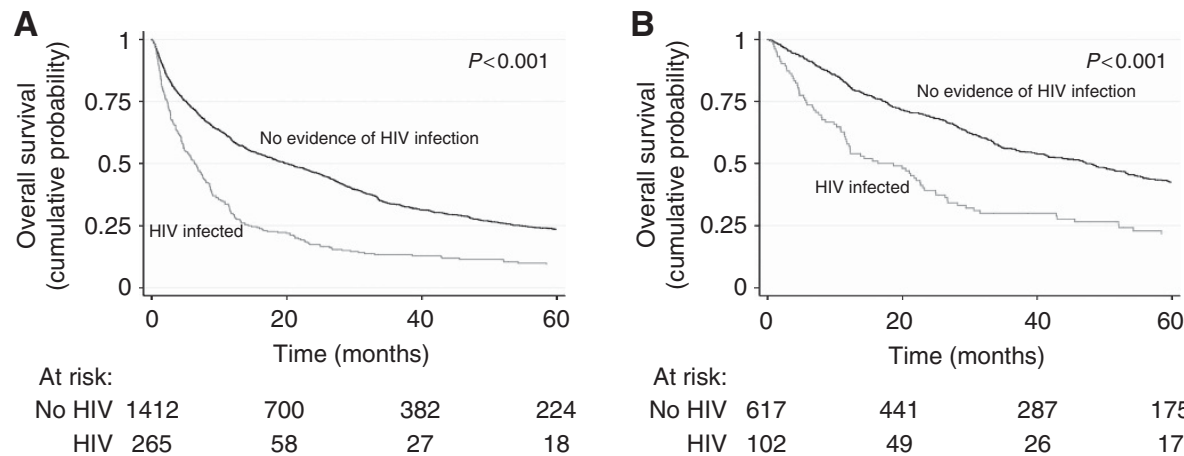

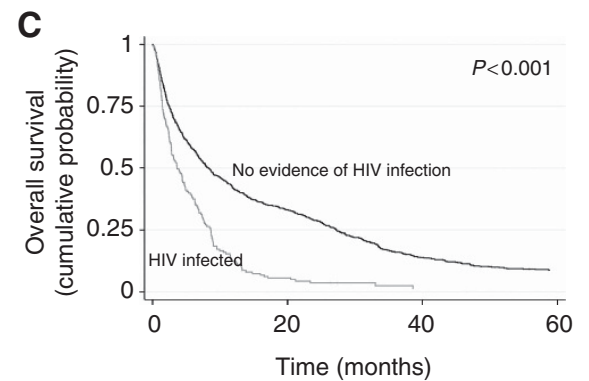

At risk: No HIV 795 HIV 163
D

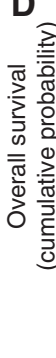

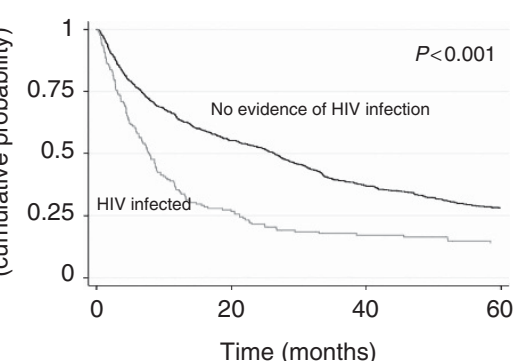

\begin{abstract}
At risk:
\end{abstract}
No HIV 971

HIV 172
534

46
E

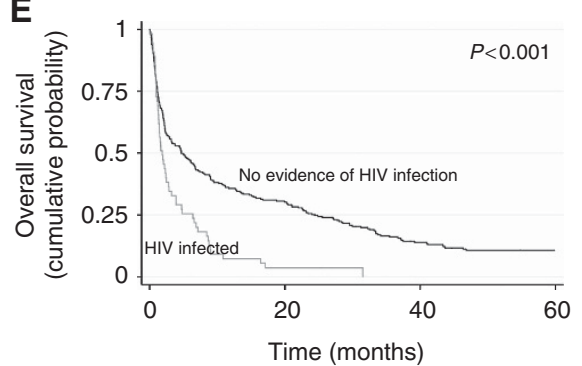

At risk:

$\begin{array}{rcccc}\text { No HIV } & 260 & 77 & 31 & 19 \\ \text { HIV } & 55 & 2 & 0 & 0\end{array}$

Figure 1. Overall survival by HIV status. (A) All patients; (B) patients with stage I-IIIA NSCLC; (C) patients with stage IIIB-IV NSCLC; (D) patients who received stage-appropriate NSCLC treatment; $(\mathrm{E})$ patients who did not receive NSCLC treatment. 


\begin{tabular}{|c|c|c|c|c|}
\hline Characteristic & $\begin{array}{l}\text { Hazard } \\
\text { ratio for } \\
\text { all-cause } \\
\text { mortality }^{a}\end{array}$ & $\begin{array}{c}95 \% \\
\mathrm{Cl}\end{array}$ & $\begin{array}{c}\text { Odds } \\
\text { ratio } \\
\text { for lung } \\
\text { cancer } \\
\text { mortality }\end{array}$ & $\begin{array}{c}95 \% \\
\mathrm{Cl}\end{array}$ \\
\hline HIV infection & 1.9 & $1.6-2.2$ & 1.7 & $1.1-2.3$ \\
\hline Age (10 years) & 1.2 & $1.0-1.4$ & 1.3 & $1.1-1.4$ \\
\hline Female & 0.6 & $0.5-0.7$ & 0.4 & $0.3-0.6$ \\
\hline \multicolumn{5}{|l|}{ Race/ethnicity } \\
\hline White $^{c}$ & - & & - & \\
\hline African-American & 1.0 & $0.9-1.1$ & 0.9 & $0.7-1.2$ \\
\hline Hispanic & 1.0 & $0.8-1.2$ & 0.8 & $0.5-1.3$ \\
\hline Other & 1.1 & $0.9-1.3$ & 1.0 & $0.7-1.6$ \\
\hline Married & 0.8 & $0.7-0.9$ & 0.6 & $0.5-0.8$ \\
\hline $\begin{array}{l}\text { Income in zip code of } \\
\text { residence above } \\
\text { median }\end{array}$ & 0.8 & $0.7-0.9$ & 0.8 & $0.6-1.1$ \\
\hline Nursing home resident & 1.4 & $1.2-1.8$ & 1.5 & $0.9-2.4$ \\
\hline Home medical services & 1.0 & $0.7-1.3$ & 0.4 & $0.2-0.7$ \\
\hline $\begin{array}{l}\text { Disability or end-stage } \\
\text { renal disease as reason } \\
\text { for medicare } \\
\text { entitlement }\end{array}$ & 0.9 & $0.8-1.1$ & 0.7 & $0.5-1.1$ \\
\hline $\begin{array}{l}\text { Modified Charlson } \\
\text { comorbidity score }\end{array}$ & 1.2 & $1.1-1.2$ & 1.4 & $1.3-1.6$ \\
\hline
\end{tabular}

Tumour stage

\begin{tabular}{|l|c|c|c|c|}
\hline $\mathrm{I}^{\mathrm{c}}$ & - & & - & \\
II & 1.2 & $0.9-1.6$ & 1.7 & $1.0-2.9$ \\
IIIA & 1.6 & $1.3-1.9$ & 2.9 & $1.9-4.3$ \\
IIIB & 3.4 & $2.8-4.0$ & 9.9 & $6.7-14.6$ \\
IV & 5.7 & $4.8-6.7$ & 20.8 & $14.6-29.7$ \\
Stage-appropriate & 0.5 & $0.4-0.6$ & 0.4 & $0.3-0.6$ \\
treatment & & & & \\
\hline
\end{tabular}

Year of cancer diagnosis

\begin{tabular}{|l|l|l|l|l|}
\hline $1996-1999^{c}$ & - & & - & \\
$2000-2003$ & 1.0 & $0.8-1.2$ & 0.8 & $0.6-1.2$ \\
$2004-2007$ & 0.9 & $0.8-1.1$ & 0.2 & $0.1-0.2$ \\
\hline
\end{tabular}

Abbreviations: $\mathrm{Cl}=$ confidence interval; $\mathrm{HIV}=$ human immunodeficiency virus.

${ }^{\mathrm{a}} \mathrm{Cox}$ proportional hazards regression model.

${ }^{\mathbf{b}}$ Conditional probability regression model.

c Reference group.

required at least two temporally separated outpatients claims or one inpatient claim, consistent with most strategies for identifying HIV-infected patients in claims data (Fasciano et al, 1998). In contrast, the study by Rengan et al (2012) identified HIV-infected patients by the presence of one or more claims; this approach may capture subjects with 'rule out' diagnoses but not true HIV infection (Klabunde et al, 2006). The finding by Rengan et al (2012) of similar OS in HIV-infected and HIV-uninfected NSCLC patients in itself suggests contamination of the HIV-infected group by HIV-uninfected persons because a higher death rate from causes other than lung cancer would be expected in the HIVinfected group, with a resultant increase in overall mortality. Furthermore, the median age of our HIV-infected NSCLC cases was 55 years compared with a median age of 75 years among the HIV-infected NSCLC cases in the study by Rengan et al (2012). A younger age distribution would be expected, based on the age demographics of HIV-infected persons (CDC, 2012) and the median age at lung cancer diagnoses in previous studies (2013), again suggesting that the HIV-infected group in the Rengan et al (2012) study may have been contaminated by persons who were not HIV-infected.

Competing risks of death are an important consideration when evaluating the association of HIV status with lung cancer prognosis (Shiels et al, 2010), as HIV-infected patients continue to experience mortality exceeding the general population (Zwahlen et al, 2009). Using competing risks methods, our results more accurately reflect the differences in the risk of lung cancer-specific death according to HIV status. Thus, our findings showing poorer lung cancer survival in HIV-infected patients suggest differences in the underlying prognosis of the disease. However, we did not observe any differences in the distribution of lung cancer stage at diagnosis between HIV-infected and -uninfected patients despite worse cancer outcomes. It is possible that ascertainment bias from increased medical contact may explain this lack of difference in stage distribution, with lung cancers being detected earlier in HIV-infected patients despite potentially more aggressive tumour behaviour.

There are several possible explanations for poorer outcomes in HIV-infected NSCLC patients. Although HIV-infected patients received similar rates of stage-appropriate therapy compared with patients without evidence of HIV in our sample, it is possible that HIV-infected patients were less tolerant of chemotherapy than patients with no evidence of HIV infection (perhaps due to interactions with cART) and therefore were not likely to receive the same intensity or duration of therapy. Additionally, data are limited on differences in the frequency of specific oncogenic mutations or other genetic tumour characteristics between HIVinfected and -uninfected patients. However, an early study comparing tumour genetics in NSCLC between patients with and without HIV demonstrated increased microsatellite instability in tumours from HIV-infected patients (Wistuba et al, 1998). The impact of high level microsatellite instability on NSCLC prognosis is unclear, but some studies suggest that it may have some correlation with poor long-term survival (Zhou et al, 2000).

Although impaired T-cell immunity associated with HIV infection may adversely affect immunologic cancer defenses, the anti-tumour immune microenvironment in chronic HIV infection and its impact on tumour behaviour has not been well studied. Although the role of $\mathrm{T}$ cells in mediating the response to lung cancer is unclear, CD4 cell infiltration in NSCLC has been associated with a more favourable prognosis, suggesting a potential protective effect (Hiraoka et al, 2006). These observations are further supported by benefits demonstrated in early-stage trials utilising therapies stimulating T-cell activity in NSCLC patients (Genova et al, 2012).

A large proportion of the HIV-infected patients included in this study became eligible for Medicare benefits because of disability, and therefore our sample may represent a subgroup of HIV-infected NSCLC patients with a history of more advanced HIV. Previous data has shown that HIV-infected patients who qualified for Medicare were likely to have been diagnosed with an AIDS-defining condition (Fasciano et al, 1998), suggesting that the HIV-infected patients in our study had a greater risk of having experienced significant immunosuppression. Thus, poor overall and lung cancer-specific survival in HIV-infected patients may potentially be associated with poorly controlled or more severe HIV disease stage.

This study has a number of strengths as well as limitations that warrant mention. Our study benefits from a relatively large number of HIV-infected cases, data originating from many centres in diverse geographic regions, long-term follow-up, and use of competing risk methods. There were differences in reasons for Medicare entitlement noted in HIV-infected NSCLC patients within SEER-Medicare compared with the overall SEER-Medicare NSCLC cohort. To mitigate these differences, we used a matching strategy to create a similar comparison group. Even after matching, significant differences remained in some covariates between 

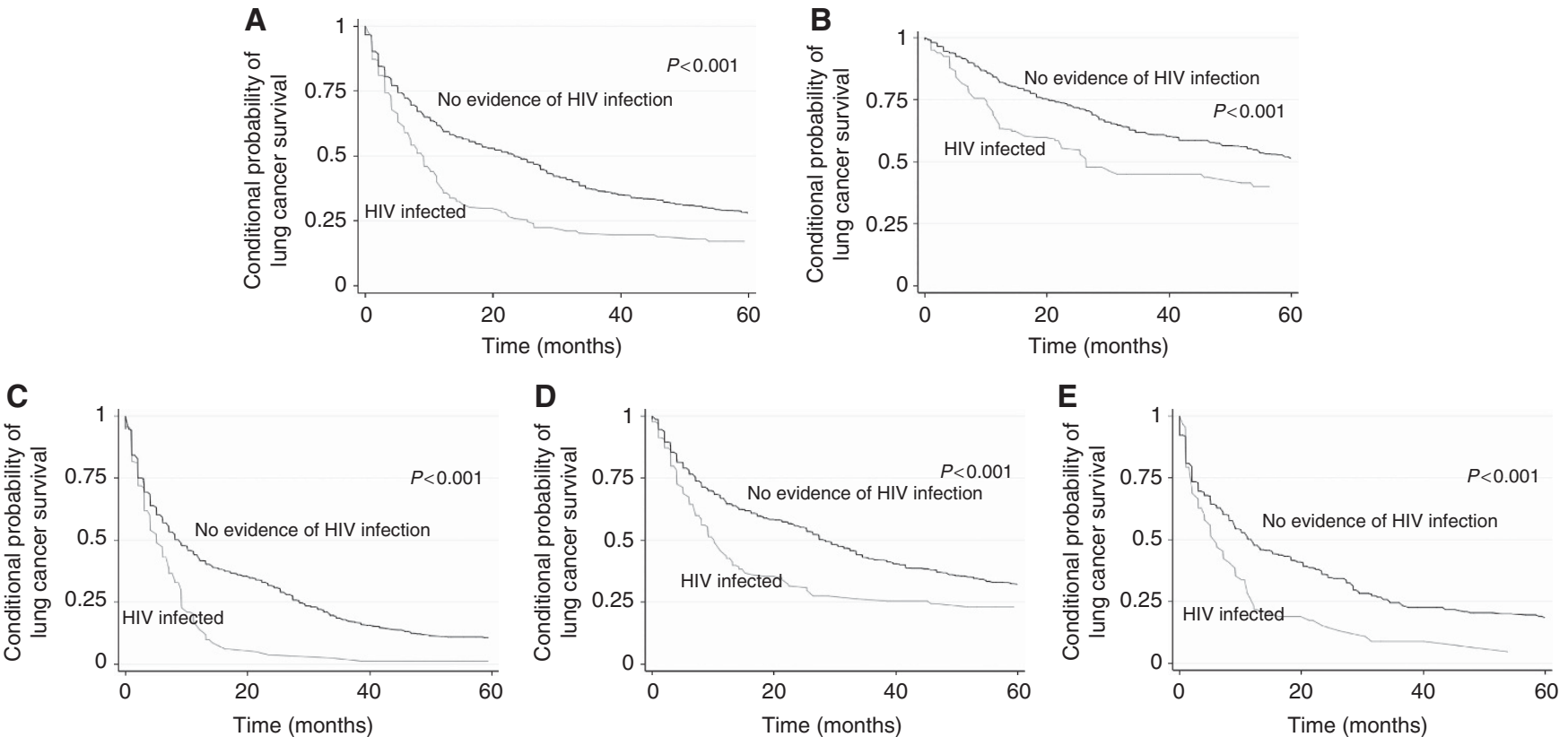

Figure 2. The CPF curves for lung cancer survival by HIV status. (A) All patients; (B) patients with stage I-IIIA NSCLC; (C) patients with stage IIIB-IV NSCLC; (D) patients who received stage-appropriate NSCLC treatment; (E) patients who did not receive NSCLC treatment.

HIV-infected and -uninfected patients in our sample; our findings remained the same after adjustment for these factors. We were also unable to confirm lack of HIV seropositivity in our comparison group. However, rates of undiagnosed HIV infection in patients undergoing treatment for solid tumours have been very low (Shrestha et al, 2012), suggesting that most of the patients without evidence of HIV infection in our study were HIV negative. Furthermore, misclassification of HIV status would have biased our results towards the null. Another limitation of our study was that SEER-Medicare has no HIV-specific clinical data, and therefore we could not evaluate the effects of severity of immunosuppression or cART on the prognosis of the patients in the sample. We also had no data on smoking, so were unable to control for the effect of smoking on survival. In addition, we also had no data on the use of epidermal growth factor receptor inhibitors as therapy because these drugs are administered orally and are not covered by traditional Medicare. Finally, our competing risks analyses were limited by the use of death certificate data to determine the cause of death, which may be inaccurate. However, death certificate validation studies suggest that determination of lung cancer as a cause of death appears to be more accurate than determination of other diagnoses (Doria-Rose and Marcus, 2009).

In our population-based cART-era data, we found that among patients with NSCLC, HIV-infected patients had a poorer prognosis than those without evidence of HIV after accounting for potential confounders and competing risks of death, suggesting more aggressive lung cancer behaviour in the setting of HIV infection. Further research is needed to evaluate the effect of specific factors associated with HIV infection, such as immunosuppression and cART use, on lung cancer prognosis.

\section{ACKNOWLEDGEMENTS}

This study was supported by the National Center for Research Resources (KL2TR000069 to KS) and the National Cancer Institute (R01CA173754 to KC and JW). We acknowledge the efforts of the Applied Research Program, NCI; the Office of Research,
Development and Information, CMS; Information Management Services (IMS), Inc., and the Surveillance, Epidemiology, and End Results (SEER) Program tumour registries in the creation of the SEER-Medicare database. This study used the linked SEERMedicare database. The interpretation and reporting of these data are the sole responsibility of the authors.

\section{CONFLICT OF INTEREST}

The authors declare no conflict of interest.

\section{REFERENCES}

Allignol A, Latouche A, Yan J, Fine J (2011) A regression model for the conditional probability of a competing event: application to monoclonal gammopathy of unknown significance. Appl Stat 60: 135-14.

Bach PB, Guadagnoli E, Schrag D, Schussler N, Warren JL (2002) Patient demographic and socioeconomic characteristics in the SEER-Medicare database applications and limitations. Med Care 40(8 Suppl): 19-25.

Biggar RJ, Engels EA, Ly S, Kahn A, Schymura MJ, Sackoff J, Virgo P, Pfeiffer RM (2005) Survival after cancer diagnosis in persons with AIDS. J Acquir Immune Defic Syndr 39: 293-299.

Bourcier V, Winnock M, Ait Ahmed M, Sogni P, Pambrun E, Poizot-Martin I, Chaffaut C, Chevret S, Trinchet JC, Salmon D (2012) Primary liver cancer is more aggressive in HIV-HCV coinfection than in HCV infection. A prospective study (ANRS CO13 Hepavih and CO12 Cirvir). Clin Res Hepatol Gastroenterol 36: 214-221.

Buell JF, Papaconstantinou HT, Skalow B, Hanaway MJ, Alloway RR, Woodle ES (2005) De novo colorectal cancer: five-year survival is markedly lower in transplant recipients compared with the general population. Transplant Proc 37: 960-961.

Centers for Disease Control (2012) HIV in the United States: At A Glance. United States Centers for Disease Control and Prevention: Atlanta, Georgia, USA. Available at: http://www.cdc.gov/hiv/statistics/basics/ ataglance.html.

Deyo RA, Cherkin DC, Ciol MA (1992) Adapting a clinical comorbidity index for use with ICD-9-CM administrative databases. J Clin Epidemiol 45: 613-619.

Doria-Rose VP, Marcus PM (2009) Death certificates provide an adequate source of cause of death information when evaluating lung cancer 
mortality: an example from the Mayo Lung Project. Lung Cancer 63: 295-300.

Fasciano NJ, Cherlow AL, Turner BJ, Thornton CV (1998) Profile of Medicare beneficiaries with AIDS: application of an AIDS casefinding algorithm. Health Care Financ Rev 19: 19-38.

Genova C, Rijavec E, Barletta G, Sini C, Dal Bello MG, Truini M, Murolo C, Pronzato P, Grossi F (2012) Ipilimumab (MDX-010) in the treatment of non-small cell lung cancer. Expert Opin Biol Ther 12: 939-948.

Guiguet M, Boue F, Cadranel J, Lang JM, Rosenthal E, Costagliola D (2009) Effect of immunodeficiency, HIV viral load, and antiretroviral therapy on the risk of individual malignancies (FHDH-ANRS CO4): a prospective cohort study. Lancet Oncol 10: 1152-1159.

Hakimian R, Fang H, Thomas L, Edelman MJ (2007) Lung cancer in HIV-infected patients in the era of highly active antiretroviral therapy. $J$ Thorac Oncol 2: 268-272.

Hiraoka K, Miyamoto M, Cho Y, Suzuoki M, Oshikiri T, Nakakubo Y, Itoh T, Ohbuchi T, Kondo S, Katoh H (2006) Concurrent infiltration by CD8 + T cells and CD4 $+\mathrm{T}$ cells is a favourable prognostic factor in non-small-cell lung carcinoma. Br J Cancer 94: 275-280.

Kirk GD, Merlo CA (2011) HIV infection in the etiology of lung cancer: confounding, causality, and consequences. Proc Am Thorac Soc 8: 326-332.

Klabunde CN, Harlan LC, Warren JL (2006) Data sources for measuring comorbidity: a comparison of hospital records and medicare claims for cancer patients. Med Care 44: 921-928.

Mocroft A, Brettle R, Kirk O, Blaxhult A, Parkin JM, Antunes F, Francioli P, D'Arminio Monforte A, Fox Z, Lundgren JD (2002) Changes in the cause of death among HIV positive subjects across Europe: results from the EuroSIDA study. AIDS 16: 1663-1671.

NCCN (2011) Clinical practice guidelines in oncology: non-small cell lung cancer. National Comprehensive Cancer Network.

NCI.gov (2013) Cause-specific Death Classification.

O'Callaghan DS, O'Donnell D, O'Connell F, O'Byrne KJ (2010) The role of inflammation in the pathogenesis of non-small cell lung cancer. J Thorac Oncol 5: 2024-2036.

Pepe MS, Mori M (1993) Kaplan-Meier, marginal or conditional probability curves in summarizing competing risks failure time data? Stat Med 12: $737-751$.

Pintilie M (2006) Competing Risks: A Practical Perspective. Wiley and Sons: West Sussex, England, USA.

Poluri A, Shah KG, Carew JF, Shaha AR, Har-El G, Lucente FE, Singh B (2002) Hodgkin's disease of the head and neck in human immunodeficiency virus-infected patients. Am J Otolaryngol 23: 12-16.

Rengan R, Mitra N, Liao K, Armstrong K, Vachani A (2012) Effect of HIV on survival in patients with non-small-cell lung cancer in the era of highly active antiretroviral therapy: a population-based study. Lancet Oncol 13: 1203-1209.

Rodrigues LK, Klencke BJ, Vin-Christian K, Berger TG, Crawford RI, Miller 3rd JR, Ferreira CM, Nosrati M, Kashani-Sabet M (2002) Altered clinical course of malignant melanoma in HIV-positive patients. Arch Dermatol 138: $765-770$.

Shiels MS, Cole SR, Chmiel JS, Margolick J, Martinson J, Zhang ZF, Jacobson LP (2010) A comparison of ad hoc methods to account for non-cancer
AIDS and deaths as competing risks when estimating the effect of HAART on incident cancer AIDS among HIV-infected men. J Clin Epidemiol 63: 459-467.

Shiels MS, Cole SR, Kirk GD, Poole C (2009) A meta-analysis of the incidence of non-AIDS cancers in HIV-infected individuals. J Acquir Immune Defic Syndr 52: 611-622.

Shrestha S, Johnson D, Porter D, Reid E, Palchinsky J, Napravnik S, Mathews W, Eron J, Saag M (2012) HIV prevalence among cancer patients in 3 urban oncology clinics. Conference on Retroviruses and Opportunistic Infections. ,Vol. Abstract \#904. Seattle, WA, USA.

Sigel K, Wisnivesky J, Gordon K, Dubrow R, Justice A, Brown ST, Goulet J, Butt AA, Crystal S, Rimland D, Rodriguez-Barradas M, Gibert C, Park L, Crothers K (2012) HIV as an independent risk factor for incident lung cancer. AIDS 26: 1017-1025.

Suneja G, Shiels MS, Melville SK, Williams MA, Rengan R, Engels EA (2013) Disparities in the treatment and outcomes of lung cancer among HIV-infected people in Texas. AIDS 27: 459-468.

Tirelli U, Spina M, Sandri S, Serraino D, Gobitti C, Fasan M, Sinicco A, Garavelli P, Ridolfo AL, Vaccher E (2000) Lung carcinoma in 36 patients with human immunodeficiency virus infection. The Italian Cooperative Group on AIDS and Tumors. Cancer 88: 563-569.

Unites States Social Security Administration (2013) Disability Evaluation Under Social Security.

Virnig BA, Warren JL, Cooper GS, Klabunde CN, Schussler N, Freeman J (2002) Studying radiation therapy using SEER-Medicare-linked data. Med Care 40(8 suppl): 49-54.

Warren JL, Harlan LC, Fahey A, Virnig BA, Freeman JL, Klabunde CN, Cooper GS, Knopf KB (2002) Utility of the SEER-Medicare data to identify chemotherapy use. Med Care 40: 55-61.

Wisnivesky JP, Smith CB, Packer S, Strauss GM, Lurslurchachai L, Federman A, Halm EA (2011) Survival and risk of adverse events in older patients receiving postoperative adjuvant chemotherapy for resected stages II-IIIA lung cancer: observational cohort study. BMJ 343: d4013.

Wistuba II, Behrens C, Milchgrub S, Virmani AK, Jagirdar J, Thomas B, Ioachim HL, Litzky LA, Brambilla EM, Minna JD, Gazdar AF (1998) Comparison of molecular changes in lung cancers in HIV-positive and HIV-indeterminate subjects. JAMA 279: 1554-1559.

Zhou X, Kemp BL, Khuri FR, Liu D, Lee JJ, Wu W, Hong WK, Mao L (2000) Prognostic implication of microsatellite alteration profiles in early-stage non-small cell lung cancer. Clin Cancer Res 6: 559-565.

Zwahlen M, Harris R, May M, Hogg R, Costagliola D, de Wolf F, Gill J, Fatkenheuer G, Lewden C, Saag M, Staszewski S, d'Arminio Monforte A, Casabona J, Lampe F, Justice A, von Wyl V, Egger M (2009) Mortality of HIV-infected patients starting potent antiretroviral therapy: comparison with the general population in nine industrialized countries. Int $J$ Epidemiol 38: 1624-1633.

This work is published under the standard license to publish agreement. After 12 months the work will become freely available and the license terms will switch to a Creative Commons AttributionNonCommercial-Share Alike 3.0 Unported License. 